\title{
正方形角柱群内熱流動における二重平均乱流熱輸送方程式の収支分析
}

\section{An analysis of budget terms of the double averaged energy equations for turbulent flows in square rod arrays}

\author{
学 ○桜井 洋太 （阪府大）学 桑田 祐丞 （阪府大） 正 須賀 一彦 (阪府大) \\ Yota SAKURAI, Osaka Prefecture University, 1-1 gakuen-chou, Naka-ku, Sakai-shi, Osaka \\ Yusuke KUWATA Osaka Prefecture University \\ Kazuhiko SUGA Osaka Prefecture University
}

\section{1. 緒論}

多孔体は表面積を大きく持ち, 高い伝熱性能を有するため, 産業界で広く活用されている. しかし, 設計のために多孔体内 部熱流動場の実験的計測を行うことは困難であり, 詳細な数值 解析も計算コストの面で現実的でない. そのため, 体積・レイ ノルズ平均を施す二重平均系における巨視的な解法が適してい るが，モデル化のための熱流動の知見は少ない．そこで，複雑 流路の解析に適している格子ボルツマン法を用いて，正方形角 柱群内共役熱流動のラージ・エディ・シミュレーションを行い, 二重平均熱輸送方程式のモデル化のためのデータを作成した.

2. ラージ・エディ・シミュレーション

本研究では, 速度場に三次元 27 方向速度多緩和時間格子ボ ルツマン法 1)を用いた. 温度場はパッシブスカラーとして扱う 三次元 19 方向速度単一緩和時間モデルを用い, 計算の安定化 のため regularization ${ }^{2)}$ を導入すると, 温度場の密度分布関数 は以下のように表される。

$$
\left|\boldsymbol{g}\left(\boldsymbol{x}+\boldsymbol{\xi}_{\alpha} \delta t, t+\delta_{t}\right)\right\rangle=\left|\boldsymbol{g}^{\boldsymbol{e q}}(\boldsymbol{x}, t)\right\rangle+\left(1-\frac{1}{\tau_{g}}\right)\left|\hat{\boldsymbol{g}}^{\prime}(\boldsymbol{x}, t)\right\rangle,
$$

ここで, $\boldsymbol{g}^{\boldsymbol{e q}}$ は平衡分布関数であり, $\hat{\boldsymbol{g}}^{\prime}$ は, 密度分布関数の非 平衡量である. 温度拡散係数は $\alpha=\alpha_{0}+\alpha_{S G S}$ となり, 緩和係 数に $\alpha=1 / 3\left(\tau_{g}-1 / 2\right) \delta t$ として関連付けられている. $\alpha_{0}$ は温 度拡散係数, $\alpha_{S G S}$ は SGS 乱流拡散係数であり, SGS 乱流プ ラントル数を定数 0.7 として $\alpha_{S G S}=\nu_{S G S} / P r_{S G S}$ のように 定めた. また, SGS モデルには WALE モデル ${ }^{3)}$ を適用した.

\section{3. 二重平均乱流熱輸送方程式}

多孔体内熱流動において，一般には固相部と流体相部の温度 が平衡状態ではない，そのため, 本研究では流体相と固相の温 度を解析した. 流体相, 固相それぞれの体積平均温度を $\left\langle T_{f}\right\rangle^{f}$, $\left\langle T_{s}\right\rangle^{s}$ とし, 分散を $\tilde{T}_{f}=T_{f}-\left\langle T_{f}\right\rangle^{f}$ とすると, それぞれの相 における二重平均熱輸送方程式は, 以下のように表される.

$$
\begin{aligned}
& \varphi \frac{\partial\left\langle\overline{T_{f}}\right\rangle^{f}}{\partial t}+\left\langle\bar{u}_{j}\right\rangle^{f} \frac{\partial \varphi\left\langle\overline{T_{f}}\right\rangle^{f}}{\partial x_{j}}=H^{f 1}+H^{f 2}+S_{f}, \\
& (1-\varphi) \frac{\partial\left\langle\overline{T_{s}}\right\rangle^{s}}{\partial t}=\frac{\partial}{\partial x_{j}}\left(\alpha_{s} \frac{\partial(1-\varphi)\left\langle\overline{T_{s}}\right\rangle^{s}}{\partial x_{j}}\right) \\
& -\underbrace{\frac{\partial}{\partial x_{j}}\left(\frac{1}{\Delta V} \int_{A} n_{j} \alpha_{s} \overline{T_{s}} d A\right)}_{S_{T s}}-\underbrace{\frac{1}{\Delta V} \int_{A} n_{j} \alpha_{s} \frac{\partial \overline{T_{s}}}{\partial x_{j}} d A}_{S_{W s}},
\end{aligned}
$$

$$
\text { ここで, }
$$$$
H^{f 1}+H^{f 2}=\frac{\partial}{\partial x_{j}}\left(\alpha_{f} \frac{\left.\partial \varphi \overline{T_{f}}\right\rangle^{f}}{\partial x_{j}}\right)-\frac{\partial}{\partial x_{j}}\left\{\varphi\left(H_{j}^{A}+\mathcal{H}_{j}\right)\right\}
$$$$
S_{f}=\underbrace{\frac{\partial}{\partial x_{j}}\left(\frac{1}{\Delta V} \int_{A} n_{j} \alpha_{f} \overline{T_{f}} d A\right)}_{S_{T f}}+\underbrace{\frac{1}{\Delta V} \int_{A} n_{j} \alpha_{f} \frac{\partial \overline{T_{f}}}{\partial x_{j}} d A}_{S_{W f}}
$$

なお， $\varphi$ は空隙率を示し，添え字の $f, s$ はそれぞれ，物理量が 流体相，固相のものであることを示す．体積平均された乱流熱 流束 $H_{j}^{A}=\overline{\left\langle u_{j}^{\prime} T_{f}^{\prime}\right\rangle^{f}}$ と分散熱流束項 $\mathcal{H}_{j}=\left\langle\tilde{\bar{u}}_{j} \tilde{\bar{T}}_{f}\right\rangle^{f}$ はモデル化 が必要な未知項である. 表面積分項であるねじれ項 $S_{T}$ と壁面 熱交換項 $S_{W}$ は流体と固体との間の熱交換の働きをする項であ り,これらの項もモデル化が必要である. 本解析対象の正方形 角柱群内熱流動では, $\mathcal{H}_{j}$ と $S_{T}$ は現れない.

\section{4. 計算領域および計算条件}

Fig.1 に計算領域と境界条件を示した. 上面 $(z=2 H)$ と下 面 $(z=0)$ では, 固相において一定の温度差 $\Delta T$ をつけて温 度を固定し，流体相においては断熱条件を設定した．また、速 度場はすべり境界条件を課した. 全方向に周期境界を適用する のが理想的であるが，上面と下面の温度の境界条件のため, こ のような境界条件を設定した。他のすべての面においては，周 期境界条件とし，流れ方向に一定の圧力差を与えた. 格子数は $337(x) \times 85(y) \times 168(z)$ とした. また, 体積平均の検查体積 (REV) の高さは, $z$ 方向の平均熱流束が線形分布となることを 確認したうえで $z=0.5 H-1.5 H$ と設定した. ここで, 検査体 積内の乱流において，上下のスリップ，断熱の境界条件の影響 を十分無視できることを確認したため, この REV 領域におい て $z$ 方向に周期境界が成り立つものとみなすことができる. 空 孔レイノルズ数 $\operatorname{Re}_{h}$ は $\operatorname{Re}_{h}=1 \sim 3000$ である. 角柱の一片の 長さ $D$ を変更して流れ場の空隙率は次の関係 $\varphi=1-(D / H)^{2}$ によって変えた. 流体のプラントル数は $\mathrm{Pr}=0.71$, 温度拡散係 数の比は $\alpha_{s} / \alpha_{f}=4.4$ とした.

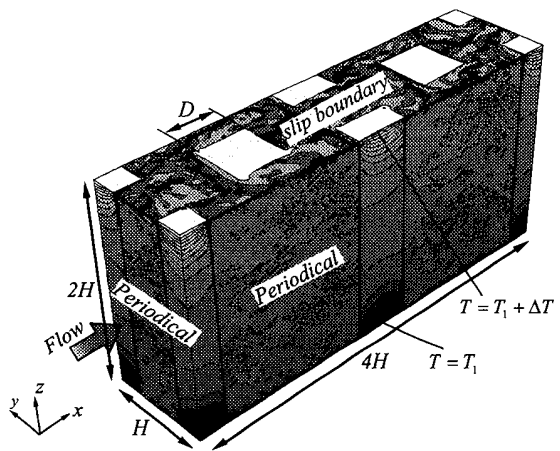

Fig.1 Computational domain and instantaneous temperature field.

\section{5. 結果と考察}

Fig.2，3 亿体積平均を施した乱流熱流束 $H_{j}^{A}$ と壁面熱交換項 $S_{W}$ を示す. Fig.2では, 体積平均乱流熱流束 $H_{j}^{A}$ が, $\mathrm{Re}_{h}=3000$ かつ $\varphi=0.91$ の条件のものを除いて, 空隙率の増加とともに 低い值へと推移している. Fig.3では, 空隙率が增加するほど, 温度の勾配が小さくなるため, 壁面熱交換項 $S_{W}$ の值が小さく なることを示している.

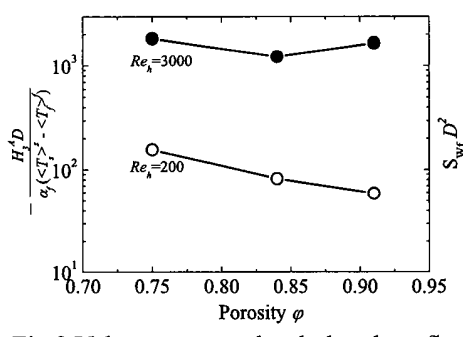

Fig.2 Volume averaged turbulent heat flux.

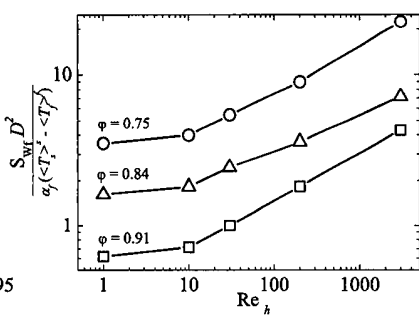

Fig.3 Wall heat transfer term.

\section{参考文献}

[1]Takashima, K., et al., Proc. Int. Comput. Mech. Symp., Kobe, Japan, 2012.

[2]Chen, H., Phys. Rev. E, 74, 046703, 2006.

[3]Nicoud, F., et al., Flow, Turbulence and Combustion, 62, No. 3, pp. 183-200, 1999. 